\title{
Marca Rio, uma grife além da cidade
}

\author{
Rio brand, a trademark that goes beyond the city
}

Marca Rio, una grife más allá de la ciudad

Patrícia Cerqueira Reis

- Doutora em Comunicação pela Escola de Comunicações e Artes da Universidade de São Paulo (ECA-USP)

- Mestre em Comunicação pela Escola de Comunicações da Universidade Federal do Rio de Janeiro (UFRJ)

- Especialista em Análise de Políticas Pública pelo Instituto de Economia da UFRJ e em Sistemas de Informação pela Universidade Federal Fluminense (UFF)

- Graduada em Comunicação Social - Publicidade pelas Faculdades Integradas Hélio Alonso (Facha)

- Pesquisadora e professora da graduação, pós-graduação e EAD da Escola Superior de Propaganda e Marketing (ESPM)

- $\quad$ Diretora de Projetos da HOD Planejamento e Gestão de Comunicação de Marcas

- E-mails: patriciareis@espm.br; patriciareis@hodcomunicacao.com.br 


\section{Resumo}

Este artigo se propõe apresentar um estudo de caso sobre a inserção da marca Rio no mercado global de cidade, no período de 2009 a 2015, e contrapor os elementos da identidade da marca Rio com as narrativas das empresas que se associam a ela para a divulgação de suas marcas institucionais e de produtos e serviços. Ao final, pretende-se avaliar o quanto essa estratégia comunicacional agrega valor a ambos os lados.

\section{PALVRAS-CHAVE: CIDADE・NARRATIVA DE MARCA・COMUNICACCÃO ORGANIZACIONAL・RELACCÕES PÚBLICAS・MARCA DE CIDADE.}

\section{Abstract}

This article aims at presenting a case study on the inclusion of the Rio trademark in the city global market, from 2009 to 2015 , and confront the elements of the identity of the Rio brand with the narratives of the companies that are associated with it for the divulgement of their institutional, products and services brands. Ultimately one intends to assess to what extent this communicational strategy adds value to both sides.

\section{KEYWORDS: CITY •BRAND NARRATIVE・ORGANIZATIONAL COMMUNICATION・PUBLIC RELATIONS・CITY BRAND.}

\section{Resumen}

Este artículo tiene como objetivo presentar un estudio de caso sobre la inserción de la marca Rio en el mercado global de la ciudad, en el espacio de 2009 a 2015, y contrapone los elementos de la identidad de la marca Rio con las narrativas de las empresas que se asocian con ella para la divulgación de sus marcas institucionales y de productos y servicios. Al final, se pretende evaluar cómo esta estrategia comunicacional añade valor a ambos lados. 
ANO 13 • NÚMERO 24 • 1ํSEM. 2016 - ORGANICOM

MARCA RIO, UMA GRIFE ALÉM DA CIDADE

cidade do Rio de Janeiro ocupa um espaço privilegiado no imaginário coletivo. Suas belezas naturais onde a praia 4 e montanha se encontram, pessoas acolhedoras e espontâneas e a possibilidade de unir trabalho e lazer no dia a dia criam um estilo de vida carioca desejado por muitos, mas que se contrapõe às mazelas de uma metrópole em desenvolvimento. A redução do contraste entre o imaginário e o real se iniciou quando uma série de transformações começou a modificar a cidade do Rio de Janeiro.

\section{A CIDADE ANTES DA MARCA}

Em 2007, as três esferas governamentais - municipal, estadual e federal - se alinharam pela primeira vez, possibilitando 0 diálogo e esforços conjuntos para o reordenamento urbano, como o da região portuária, onde parte expressiva dos terrenos pertencentes à União e ao Estado inviabilizava a reurbanização do local pela Prefeitura. A parceria também permitiu investimentos federais para os projetos de mobilidade urbana e de segurança pública (Oliveira Filho; Giambiagi, 2015).

Como resultado das transformações resultantes dessa parceria, o Rio do Janeiro foi eleito, em 2010, uma das dez cidades mais dinâmicas do mundo pelo Global Metro Monitor', que fez uma comparação do dinamismo econômico das 150 maiores metrópoles do mundo no período antes da crise internacional (1993-2007) com o do período posterior (2008-2010). 0 Rio de Janeiro, que ocupava o 100ํ lugar no ranking pré-crise, passou a ocupar o 10ํlugar no ranking pós-crise, de acordo com André Urani e Fabio Giambiagi (2011). Para esses autores, o Rio de Janeiro foi poupado da crise internacional e se tornou capaz de atrair investimentos públicos e privados em função:

(a) dos esforços para "arrumar a casa" na administração pública, tendo a prefeitura e o governo do estado obtidos graus de investimento das principais agências de risco internacionais;

(b) dos "polpudos" empréstimos dos órgãos multilaterais, que recompuseram sua capacidade de investimento;

(c) de uma sociedade civil mobilizada para criar instrumentos voltados a monitorar e avaliar a qualidade dos gastos públicos;

(d) de uma estratégia de "soma de forças" em prol do Rio de Janeiro orquestrada pelo governo estadual, capaz de trazer de volta os investimentos do governo federal;

(e) da queda significativa dos principais indicadores de violência com o início do processo de pacificação; e

(f) da melhoria do ambiente de negócios e uma política industrial ativa.

Todos esses elementos somados ao cenário econômico, político e social positivo do país até 2014, também levou a cidade do Rio de Janeiro a ser escolhida para sediar diversos eventos de importância e visibilidade mundial, como: a Conferência das Nações Unidas sobre Desenvolvimento Sustentável - Rio+20, em 2012; a Jornada Mundial da Juventude, promovida pela Igreja Católica, e a Copa das Confederações de Futebol, em 2013; a Copa do Mundo de Futebol, em 2014; e os Jogos Olímpicos e Paraolímpicos, em 2016.

Eventos de alta visibilidade são considerados como as melhores oportunidades de promoção internacional das cidades que os sediam (Anholt, 2006; Saffron, 2013; RI, 2014). Representantes de diferentes setores, público e privado, comemoraram as expectativas positivas de desenvolvimento e crescimento econômico que a realização dos eventos apresentava. Entretanto, questionamentos foram feitos sobre a forma como a cidade foi preparada para os eventos.

1 Publicação conjunta da London School of Economics e da Brooking Institution. 
Para Carlos Vainer (2011), o megaevento concentra toda a identidade da cidade em um único símbolo, "seja a mulher bonita de Ipanema ou uma paisagem da Zona Sul", reduzindo o conceito sociológico de cidade fundamentado em tamanho, densidade e diversidade, "porque ela vende não o que ela é, e sim o que quer parecer".

Ricardo Freitas e Vania Fortuna reforçam essa abordagem, lembrando que em geral os megaeventos "se inscrevem definitivamente na história da cidade na qual acontecem, alterando seu status quo" e que muitas vezes as cidades são "maquiadas para receber esses acontecimentos e não efetivamente adaptadas para que aquela atividade traduza algo da cultura local ou passe a fazer parte dela" (Freitas; Fortuna, 2008).

Fernanda Sánchez (2010) complementa as críticas trazendo o conceito de cidades-mercadoria como sendo aquelas que passam a ser vendidas dentro das políticas de Estado que cumprem uma agenda estratégica de transformações para inserir as cidades nos fluxos globais. "Nesse contexto, não basta renovar as cidades, é preciso vendê-las e, ao fazê-lo, vende-se a imagem da cidade renovada" (Sánchez, 2010, p. 50).

As transformações da cidade do Rio de Janeiro de 2009 a 2013 ocorreram entre os debates acadêmicos e as orientações de consultorias e bancos de fomento internacionais, mas claramente marcadas por um forte otimismo tanto local quanto internacional.

Em 2013 a política pública implementada é colocada em cheque com o aumento significativo da violência urbana. No final de 2014 e no decorrer de 2015, a instabilidade é reforçada pela crise econômica causada pela redistribuição dos royalties do petróleo entre os estados da União e pela queda significativa do valor do barril no mercado internacional. Nesse cenário, uma sequência de escândalos de corrupção é deflagrada no país, causando uma das maiores crises institucionais de nossa história.

Entretanto, mesmo frente a essas adversidades, a cidade do Rio de Janeiro, eleita para sediar os Jogos Olímpicos e Paraolímpicos de 2016, manteve seu posicionamento de ser uma "Cidade Maravilhosa: a melhor cidade do hemisfério Sul para se viver, trabalhar e conhecer", estruturado em um planejamento estratégico que privilegiou as transformações urbanas, a alta visibilidade e a promoção da cidade (Rio, 2013). Embora não tendo apresentado uma logomarca para a cidade, a prefeitura, no período de 2009 a 2016, realizou um processo de construção da identidade marca Rio, como veremos a seguir.

\section{A MARCA RIO}

A fim de compreender a construção da identidade da marca Rio, optei, metodologicamente, por entrevistas em profundidade. Em 2013, foram feitas dez entrevistas com representantes das seguintes entidades e organizações: Prefeitura, Rio Negócios, Empresa Olímpica Municipal, Instituto Pereira Passos, Riotur, Turisrio e Comitê Organizador da Copa de 2014. Em 2014, a pesquisa foi complementada com mais cinco entrevistas com representantes da Secretaria de Imagem do Rio, da Coordenação de Relações Internacionais do Gabinete do Prefeito, do Consorcio Porto Maravilha, do Comitê Rio 450 anos e da Assessoria de Comunicação da Prefeitura.

Além das entrevistas, analisei os projetos presentes nos planos estratégicos do Rio de Janeiro para os períodos 20092012 e 2013-2016, assim como os esforços comunicacionais no período 2009-2015, a fim de compreender a composição da identidade da marca Rio. Esses procedimentos seguiram as orientações metodológicas para estudos de caso de Robert Yin (2001) sobre fontes de evidências em entrevistas, documentos e registros de arquivos. 
Os resultados das análises foram sobrepostos aos estudos sobre modelos de marcas de cidades propostos por Simon Anholt (2006), pelo Reputation Institute (2014), por Saffron (2013), Berrone e Ricart (2015) e Michalis Kavaratzis (2004). Tal sobreposição indicou lacunas conceituais existentes nesses modelos relacionadas a como tornar a marca da cidade mais aderente ao lugar e às pessoas.

As reflexões provenientes dos estudos e das análises levaram à proposição dos elementos que compõem a identidade de uma marca de cidade, chamado de "composto de marcas de cidades"2.

A Figura 1 apresenta a ordenação dos elementos da identidade da marca Rio, identificados nas entrevistas e nos documentos citados anteriormente, categorizados de acordo com o "composto de marcas de cidades".

Figura 1 - Elementos da identidade da marca Rio

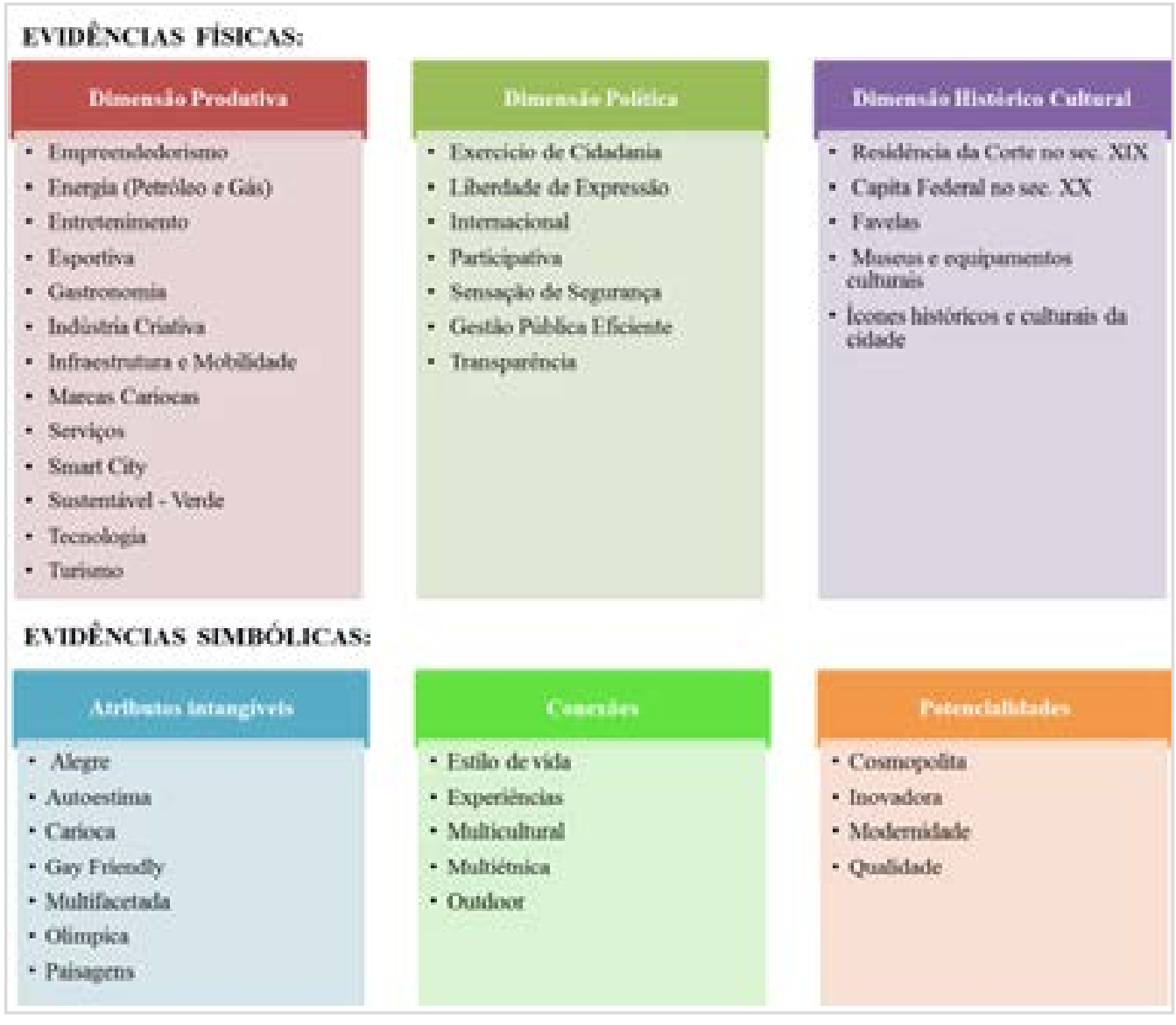

Fonte: Adaptado de Reis, 2016.

\section{AS NARRATIVAS DAS EMPRESAS SOBRE O RIO DE JANEIRO}

Entende-se por narrativa todo ato de expor um ou uma série de acontecimentos, encadeados em uma ordem determinada pelo narrador, através de palavras, imagens ou uma combinação das mesmas. Para Roland Barthes (1993, p. 251), a "narrativa está presente no mito, lenda, fábula, conto, novela, epopeia, história, tragédia, comédia, mímica, pintura, vitrais de janelas, cinema, histórias em quadrinhos, notícias, conversação". As narrativas são construídas com base no estabelecimento de memórias na estrutura mental do narrador ou do conjunto de narradores. 0 ser humano não se lembra de algo sozinho, e as memória e lembranças são produto da sociedade e do meio em que se vive (Torino, 2013).

Nesse contexto, as narrativas das marcas das empresas contribuem de forma significativa na construção da memória coletiva e, consequentemente, da memória individual. Reforça esse aspecto a perspectiva do historiador Michael Pollak de 
que a memória individual e a memória coletiva são, basicamente, os acontecimentos vividos pessoalmente, assim como os acontecimentos vividos pela coletividade à qual o indivíduo sente pertencer (Oliveira, 2009, p. 8). Paulo Nassar (2006) complementa essa abordagem lembrando que um dos maiores desafios para as marcas atualmente é resgatar e conservar as memórias. Estas são compostas pelo conjunto de sensações, lembranças e experiências, boas e ruins, que as pessoas guardam da relação direta com aquilo que a marca simboliza.

Assim, entre as estratégias usadas pelas corporações para se aproximar de seus públicos, uma delas diz respeito a referenciar a memória ou os sonhos que as pessoas possuem sobre a cidade do Rio de Janeiro. Ao utilizar essa estratégia, a comunicação corporativa o faz por dois caminhos: ou vincula os elementos associados à marca Rio à identidade da marca corporativa, elaborando suas estratégias de "comunicação institucional" (Kunsch, 2003; Yanaze, 2011), ou vincula os elementos associados à marca Rio ao posicionamento das marcas de produtos e serviço, elaborando suas estratégias de "comunicação mercadológica" (Kunsch, 2003; Yanaze, 2011). Entretanto, não se trata de uma estratégia de um caminho de mão única. Quando uma marca corporativa ou de produto ou serviço se vincula aos elementos da marca Rio, ela também carrega para a marca Rio uma forte conexão com essas empresas, produtos e serviços.

A fim de demonstrar a articulação entre as marcas corporativas e de produtos e serviço e os elementos da identidade da marca Rio, optei por dois caminhos metodológicos de aquisição de evidências para o estudo de caso (Yin, 2001). Primeiro, selecionei, através de pesquisa na web, exemplos de produtos e serviços lançados com inspiração no Rio de Janeiro. Em seguida, identifiquei o conjunto de marcas eleitas como as "marcas dos cariocas"3. Por fim, contrapus os elementos da marca Rio mostrados na Figura 1 (acima) aos casos apresentados, a fim de analisar quais elementos da identidade da marca Rio são reforçados pelas narrativas das empresas, quais são enfraquecidos e o quanto essa estratégia comunicacional agrega valor a ambos os lados.

\section{Produtos e serviços com inspiração no Rio de Janeiro}

\section{O Boticário}

O Boticário lançou duas linhas de cosméticos ligados à cidade. A primeira, em 2013, foi a "Make B. Rio sixties", que teve como proposta remeter aos anos 1960 da cidade do Rio de Janeiro. A linha era formada por maquiagens, acessórios e fragrância que fazem referencias a ícones da cidade. 0 blush apresentava em sua forma original o formato dos Arcos da Lapa e o duo de sombras remetia ao calçadão de Copacabana.

Figura 2 - Produtos Boticário Rio Sixties

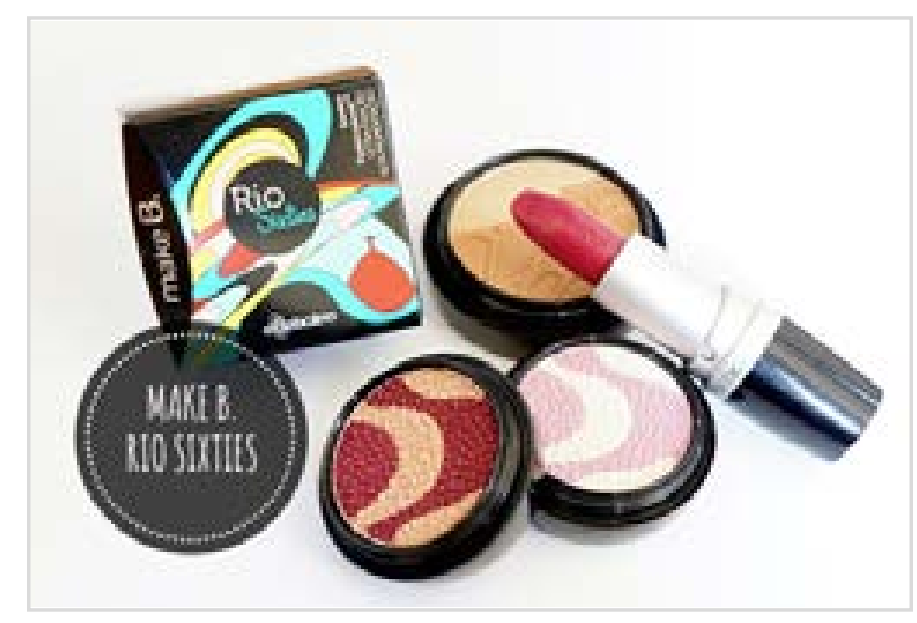

Fonte: Site de 0 Boticário. Disponível em: www.boticario.com.br. Acessado em 10/2015.

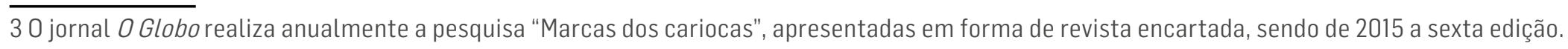


Em 2014, 0 Boticário lançou a linha "Rio, eu te amo" composta por quatro fragrâncias: Rio que encanta, Rio que anima, Rio que curte e Rio que vibra, como parte do movimento "Rio, beleza que inspira" e complementar ao lançamento do filme Rio, eu te amo. Todas as embalagens dos produtos remetiam às características do Rio de Janeiro, bem como seus locais famosos. "Rio que encanta" mostra uma visão da cidade a partir do monumento do Cristo Redentor; "Rio que anima" retrata a famosa boemia da Lapa, com um close na Fundição Progresso e os Arcos da Lapa no fundo; "Rio que curte" exibe a imagem do bonde de Santa Teresa; "Rio que vibra" tem como cenário a Praia de Copacabana. A empresa divulgou em sua comunicação publicitária que as fragrâncias eram "leves como o verão carioca".

Figura 3 - Perfumes Rio, eu te amo

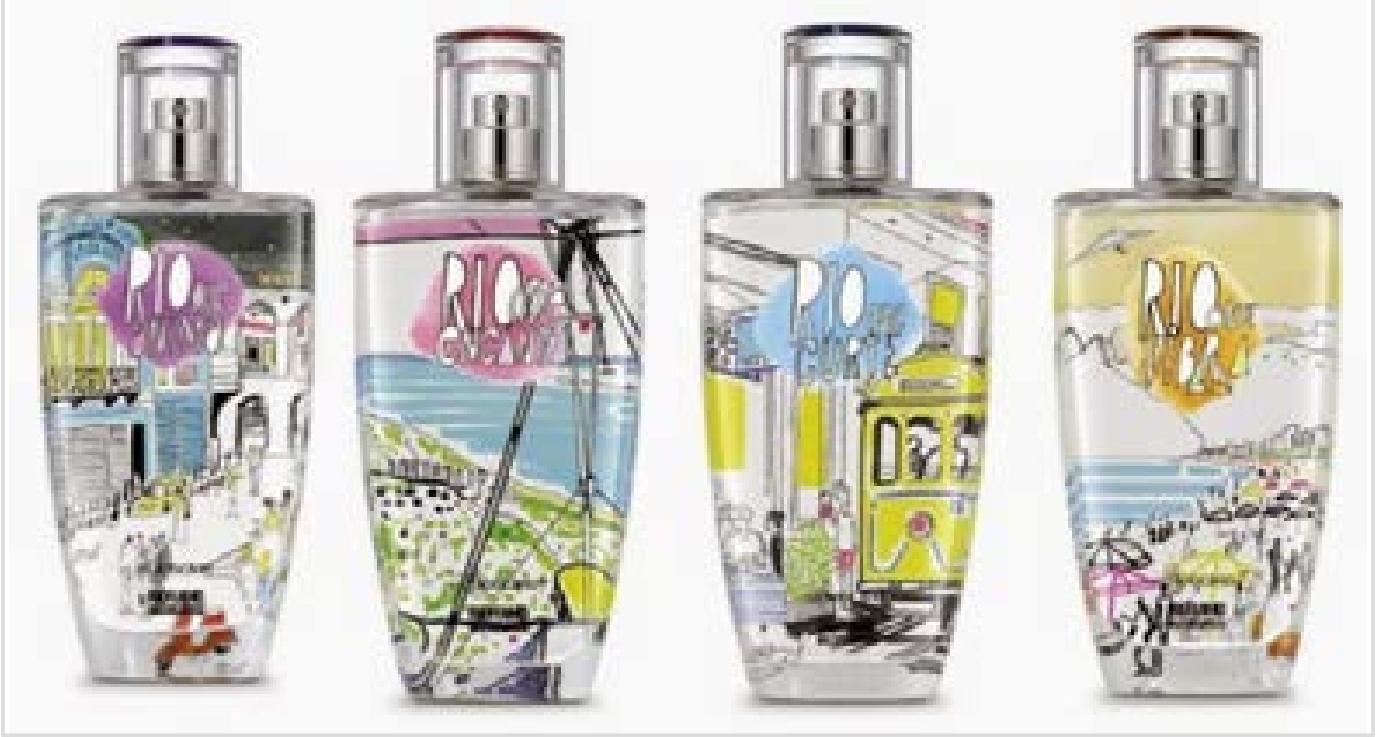

Fonte: Site de 0 Boticário. Disponível em www.boticario.com.br. Acessado em 10/2015.

A Eudora, marca pertencente ao grupo 0 Boticário, lançou em 2014 uma linha dedicada a homenagear a cidade do Rio de Janeiro, inspirada no jeito de viver descontraído do carioca. Chamada de "Soul radar Rio", a linha contou com dezessete produtos incluindo colônia, hidratante, sabonete e maquiagem.

Figura 4 - Linha Soul Radar Rio Eudora

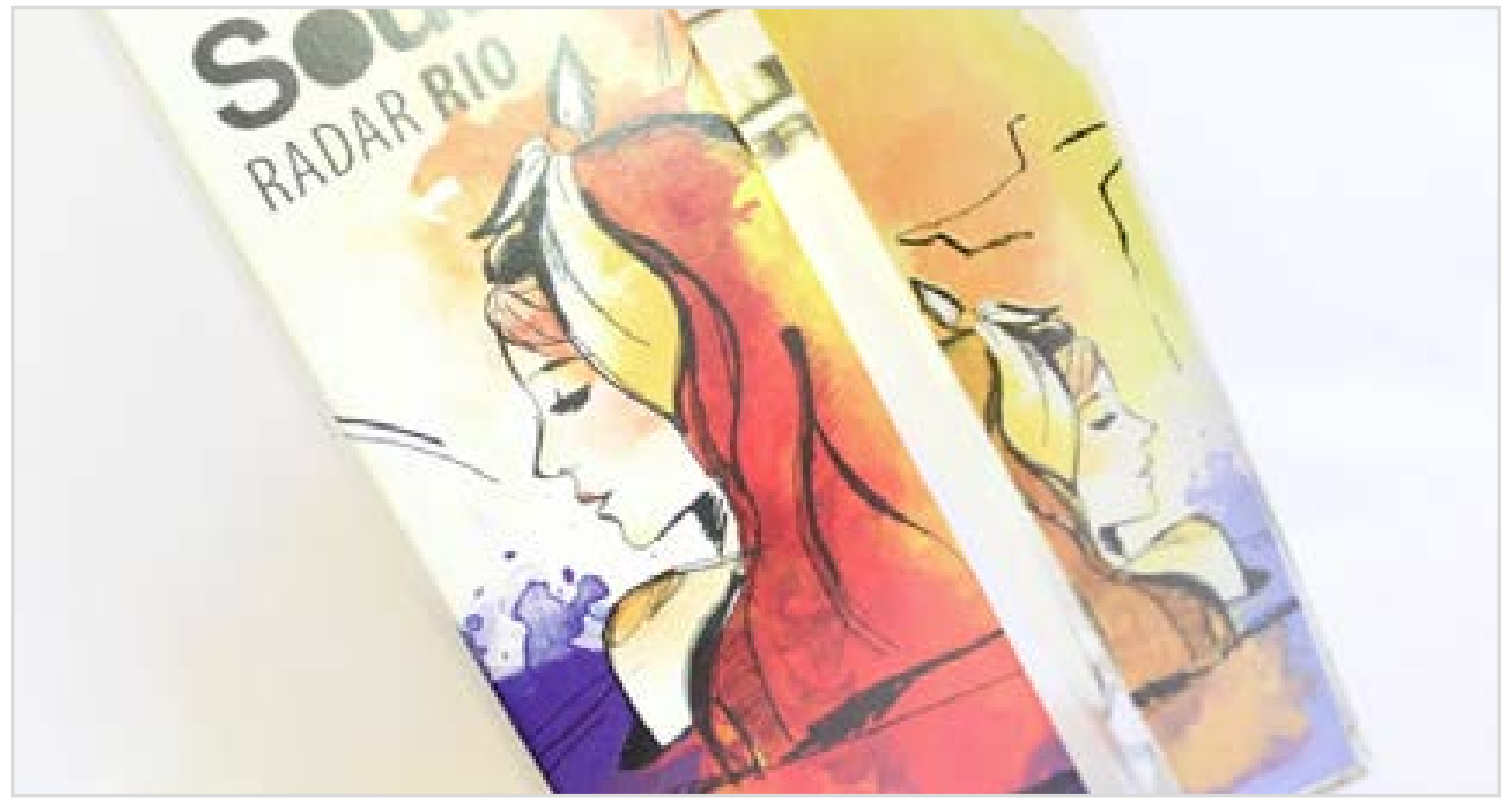

Fonte: Blog Evelyn Regly. Disponível em http://www.edobabado.com.br/ a-colecao-soul-radar-rio-da-eudora. Acessado em 10/2015. 


\section{Sandálias Ipanema, da Grendene}

As Sandálias Ipanema, lançadas em 2001, mantêm até hoje o desenho do calçadão da orla de Ipanema na base do calçado como sua principal e mais marcante característica.

\section{Havaianas, da Alpargatas}

Foram lançadas duas edições de Havaianas em homenagem ao Rio de Janeiro, usando como motivação os eventos esportivos sediados na cidade: a Copa Fifa 2014 e os Jogos Olímpicos e Paraolímpicos Rio 2016. Para a Copa do Mundo, foi elaborada uma versão para cada cidade-sede e para os Jogos Olímpicos se desenvolveram diferentes designs, sempre se referindo a ícones da cidade.

Além dessas duas versões especiais, a Alpargatas lançou em 2015 uma linha de havaianas inspirada na orla da Zona Sul da cidade do Rio de Janeiro. São doze modelos, cada um com a particularidade de cada posto da praia e mostrando a visão dos cariocas sobre a cidade. A linha é comercializada somente nas lojas próprias do Rio de Janeiro e em lojas-conceito da marca em São Paulo, localizadas na Rua Oscar Freire e no Shopping Center Iguatemi (Dias, 2015).

Figura 5 - Havaianas

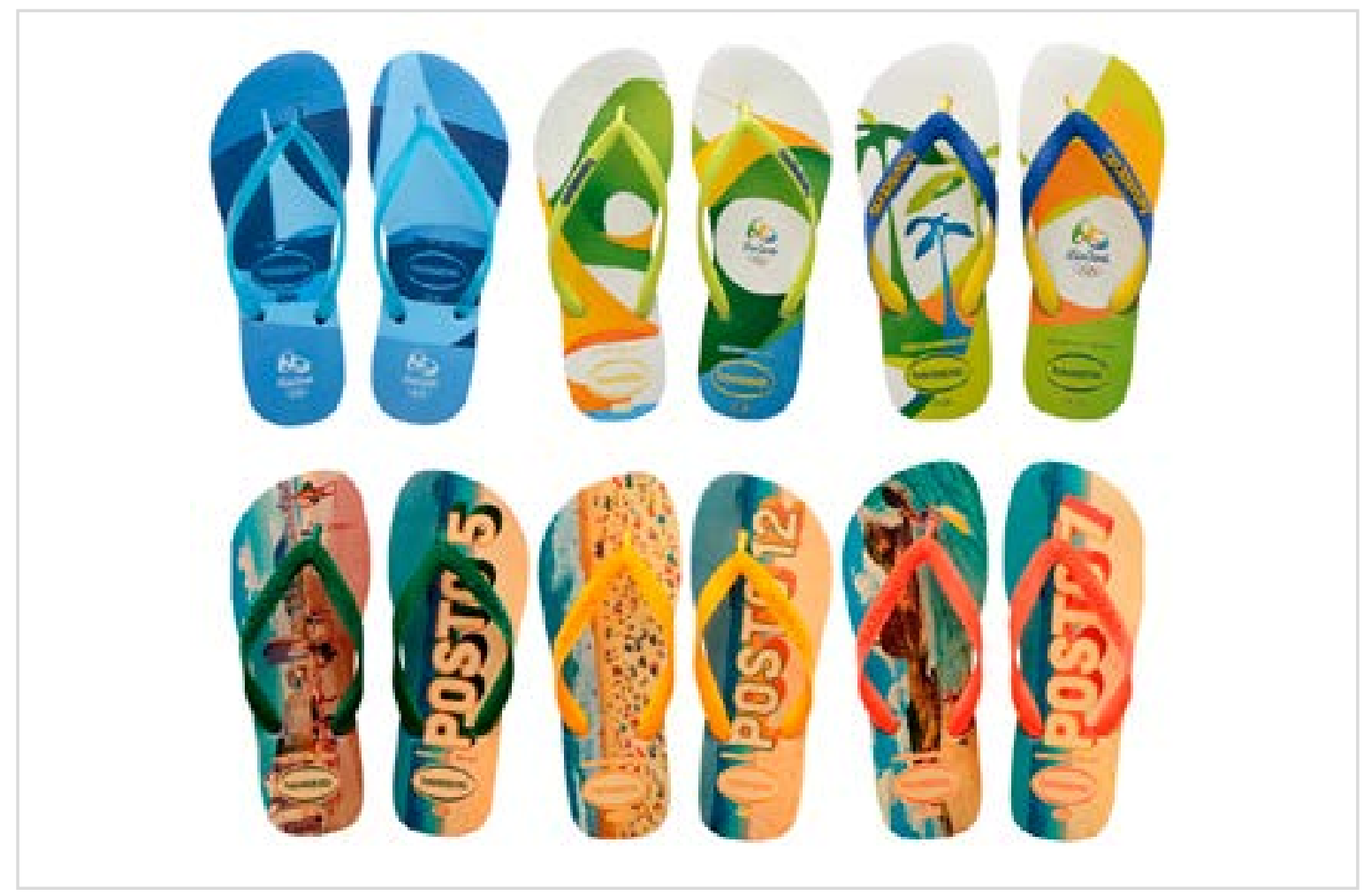

Fonte: Site Havaianas. Disponível em www.havaianas.com.br. Acesso em 10/2015.

\section{Rede Bourbon Hotéis \& Resorts}

A Rede Bourbon Hotéis \& Resorts também se apropriou do Rio de Janeiro para lançar uma nova marca de hotéis. Batizada de Rio Hotel By Bourbon, a marca pretendeu incorporar a identidade do Rio de Janeiro, trazendo para seus clientes alegria, diversidade, conveniência, inovação e descontração. A proposta era oferecer quartos funcionais, confortáveis, mas sem luxo e com um ótimo custo/benefício, podendo atender a hóspedes a negócios ou lazer. 0 Rio Hotel By Bourbon possui onze unidades nos estados do Rio de Janeiro, São Paulo, Paraná, em cidades do Nordeste brasileiro e em Ciudad Del Este, no Paraguai (Browne, 2015). 
Figura 6 - Rio Hotel By Bourbon

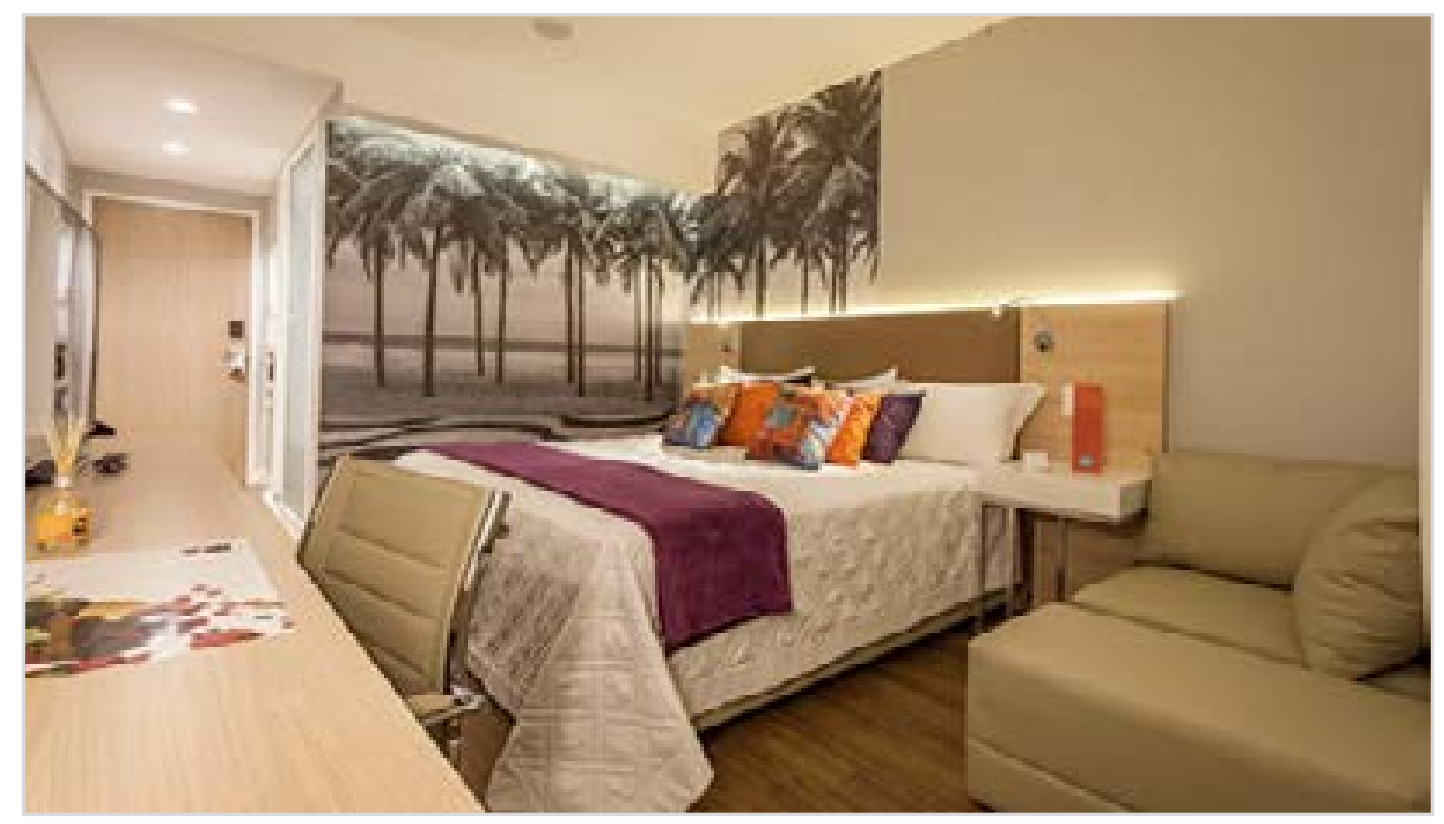

Fonte: Site Bem Estar Turismo. Disponível em https://www.bemparana.com.br/ noticia/411623/rio-de-janeiro-inspira-uma-nova-marca-de-hotel. Acesso em 10/2015.

\section{Riachuelo}

Em 2010 a Riachuelo, em parceria com o designer de moda Oskar Metsavaht, desenvolveu a coleção "Rio de Janeiro", com peças que traduziam o olhar do designer sobre a cidade. Com modelagens amplas e confortáveis, a coleção foi lançada nas lojas Riachuelo com itens femininos, masculinos, acessórios e moda de praia. (CR Press, 2010).

\section{Melissa}

A Melissa, marca de sandálias femininas para jovens, lançou em 2015 sua coleção Verão 2016 inspirada no Rio de Janeiro. A ideia da coleção é prestar uma homenagem à cultura, aos bairros, à praia e ao estilo de vida cariocas, com uma coleção multicolorida. (FFW 2015).

Figura 7 - Sandálias Melissa - Coleção Rio de Janeiro

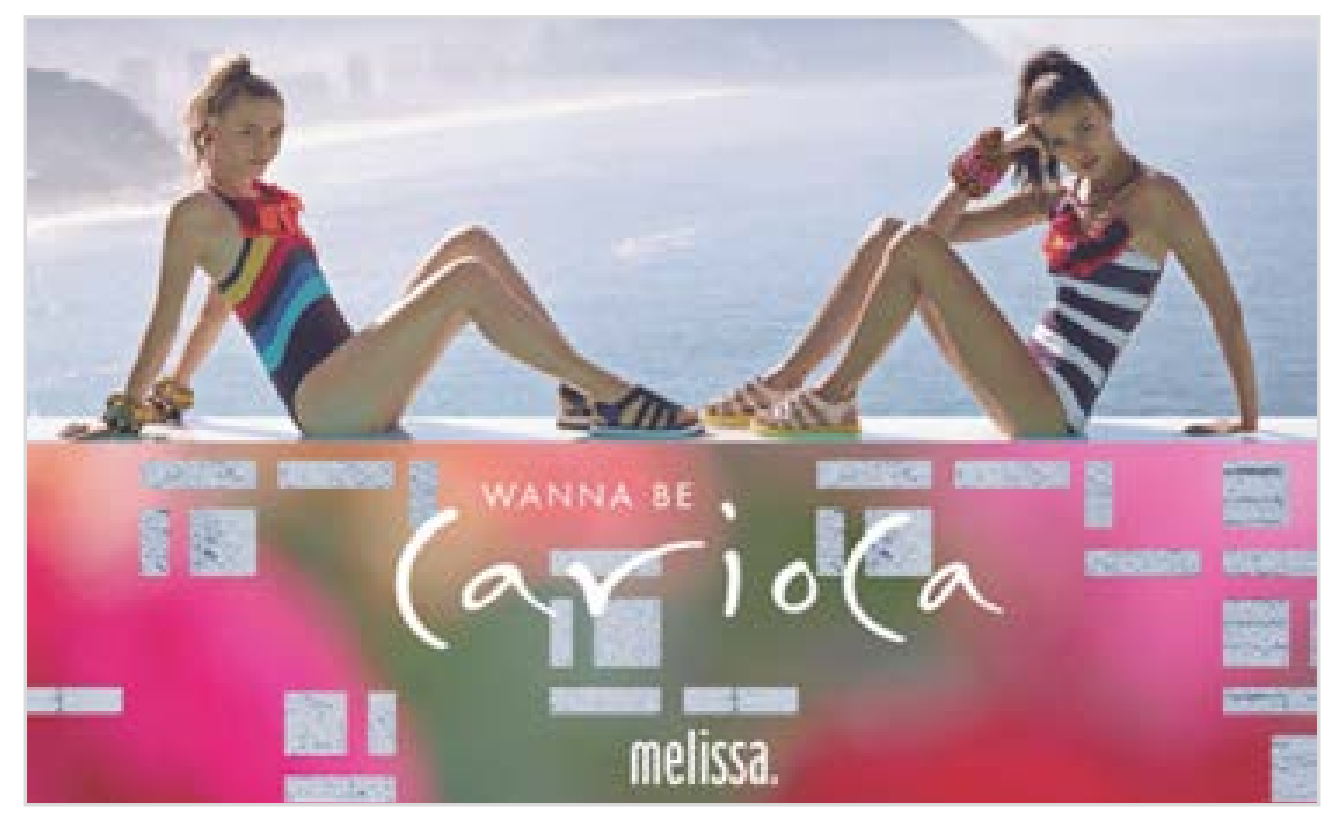

Fonte: Site da Melissa. Disponível em www.melissa.com.br/blog/colecaoverao-2016-inspirada-no-rio. Acesso em 10/2015. 


\section{Kibon e Farm}

As marcas Kibon e Farm desenvolveram, de maneira conjunta, uma versão de picolé em homenagem aos 450 anos da cidade do Rio de Janeiro. Lançado no dia 15 de janeiro de 2015, no sabor mate com limão, ele remete diretamente a um dos produtos icônicos da cidade, o mate vendido nas praias.

O picolé foi vendido durante o verão nas regiões Sul e Sudeste do Brasil nos pontos de venda tradicionais da Kibon. Além disso, o produto também pôde ser encontrado nas lojas da Farm no Rio de Janeiro, em São Paulo, Belo Horizonte e no Espírito Santo. A diferença da venda nas lojas da Farm para os pontos da Kibon foi que os picolés na Farm foram disponibilizados para venda em geladeiras customizadas, criadas especialmente para armazenar o produto. A embalagem do produto foi criada pela Farm, no modelo máxi chita, um dos florais mais emblemáticos e reconhecidos da empresa (Unilever, 2015).

Figura 8 - Picolé mate com limão

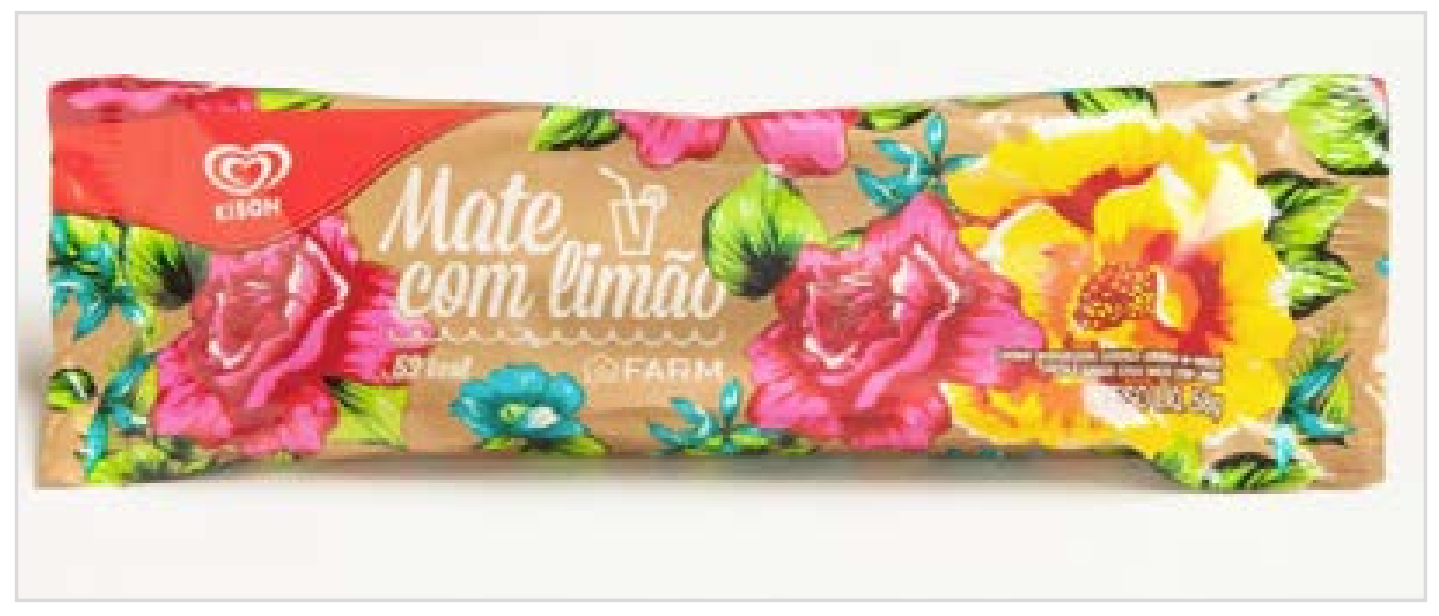

Fonte: Site da Kibon. Disponível em http://www.kibon.com.br. Acesso em 10/2015.

\section{La Frutta-Nestlé}

Em 2015, em comemoração aos 450 anos do Rio de Janeiro, a Nestlé planejou lançamentos especiais na linha La Frutta, se estendendo até o início de 2016. Além de mudar a identidade visual do uniforme de sorveteiros, carrinhose freezers, ela lançou o picolé La frutta+coco, eleito para circular até setembro de 2015 com uma embalagem especial comemorativa ao aniversário da cidade. No segundo semestre de 2015, a empresa colocou no mercado sorvetes do portfólio La frutta+, com os picolés +coco, + manga e +morango, além dos sorvetes em pote morango+framboesa, coco+abacaxi e manga+maracujá, todos remetendo aos 450 anos da cidade. Esses lançamentos deram sequência ao planejamento iniciado em março de 2015 e finalizado em fevereiro de 2016.

\section{As marcas dos cariocas}

Desde 2009, o jornal 0 Globo realiza um levantamento sobre as "marcas cariocas" que, segundo a pesquisa, "traduzem a diversidade característica do Rio de Janeiro por misturarem praia, cachoeira, verde e agitação urbana" . As cinco principais marcas foram descritas com as narrativas produzidas pelas próprias marca para justificarem por que elas são a "cara do Rio".

- Havaianas - líder na categoria desde 2013, a marca relaciona-se com a cidade por considerar "o Rio a região do país que mais explicita a alegria de viver dos brasileiros". A empresa Alpargatas acredita tanto nessa relação entre a 
marca e a cidade que criou a serie The Posto Code com seis episódios exibidos em outubro de 2015 na Sony sobre as diferentes "tribos" que ocupam os postos da orla da Zona Sul carioca.

- Kibon - identifica-se com o "clima, a alegria e a espontaneidade do carioca" e por isso oferece um produto exclusivo que é o picolé mate com limão (ícone das praias cariocas vendido em latões por ambulantes).

- Coca-Cola - relaciona-se com o Rio através de "ações ligadas ao cotidiano do carioca", sendo patrocinadora dos Jogos Olímpicos e Paraolímpicos e do Revezamento da Tocha. A marca também é apoiadora de pontos turísticos como 0 Trem do Corcovado e o Aquário do Rio (AquaRio).

- Matte Leão - de propriedade da Coca-Cola, em 2015 a empresa lançou o mate com limão a granel referenciando um ícone histórico das praias cariocas desde 1950. Relaciona-se com o Rio se referindo ao "sol, calor, sorriso no rosto e Matte Leão gelado o ano inteiro".

- Adidas - segundo a empresa, identifica-se com o "DNA esportivo que a cidade tem, não só pela beleza da paisagem".

As marcas ao serem referenciadas como identitárias para o morador da cidade estabelecem também uma conexão direta com a identidade da marca da cidade.

Na Tabela 1 pode ser vista contraposição dos elementos da identidade marca Rio apresentados na Figura 1 com as narrativas das empresas que foram analisadas.

Tabela 1 - Contraposição dos elementos da identidade da marca Rio com as narrativas das empresas

\begin{tabular}{|l|l|}
\hline \multicolumn{1}{|c|}{ Empresas } & \multicolumn{1}{|c|}{$\begin{array}{c}\text { Elementos da identidade da marca Rio } \\
\text { que foram reforçados nas narrativas das empresas }\end{array}$} \\
\hline O Boticário & $\begin{array}{l}\text { Ícones históricos e culturais da cidade; paisagens; estilo de } \\
\text { vida carioca; experiências; outdoor. }\end{array}$ \\
\hline Sandálias Ipanema, da Grendene & Paisagens; estilo de vida. \\
\hline Havaianas, da Alpagartas & $\begin{array}{l}\text { Alegre; olímpica; paisagens; estilo de vida; multifacetada; } \\
\text { multicultural; multiétnica. }\end{array}$ \\
\hline Rede Bourbon Hotéis \& Resorts & Turismo; alegre; paisagens; estilo de vida; qualidade. \\
\hline Riachuelo & Autoestima; carioca; estilo de vida. \\
\hline Melissa & Carioca; paisagens; estilo de vida. \\
\hline Kibon e Farm & Carioca; paisagens; estilo de vida. \\
\hline La Frutta - Nestlé & Carioca; estilo de vida. \\
\hline Kibon & Alegre; carioca; paisagens. \\
\hline Coca-Cola & Ícones históricos e culturais da cidade; Carioca; olímpica. \\
\hline Matte Leão & Alegre; paisagens; estilo de vida. \\
\hline Adidas & Esportiva; olímpica. \\
\hline
\end{tabular}


As narrativas dos casos estudados não enfraquecem nenhum dos elementos da identidade da marca Rio.

A fim de ilustrar o grau de reincidência dos elementos da identidade da marca Rio nas narrativas das empresas, aplicamos as palavras no sistema Tag Crowd, que permite gerar uma nuvem onde aquelas com mais reincidência aparecem com destaque, como demonstrado na Figura 9.

Figura 9 - Nuvem dos elementos da marca Rio presentes nas narrativas das empresas

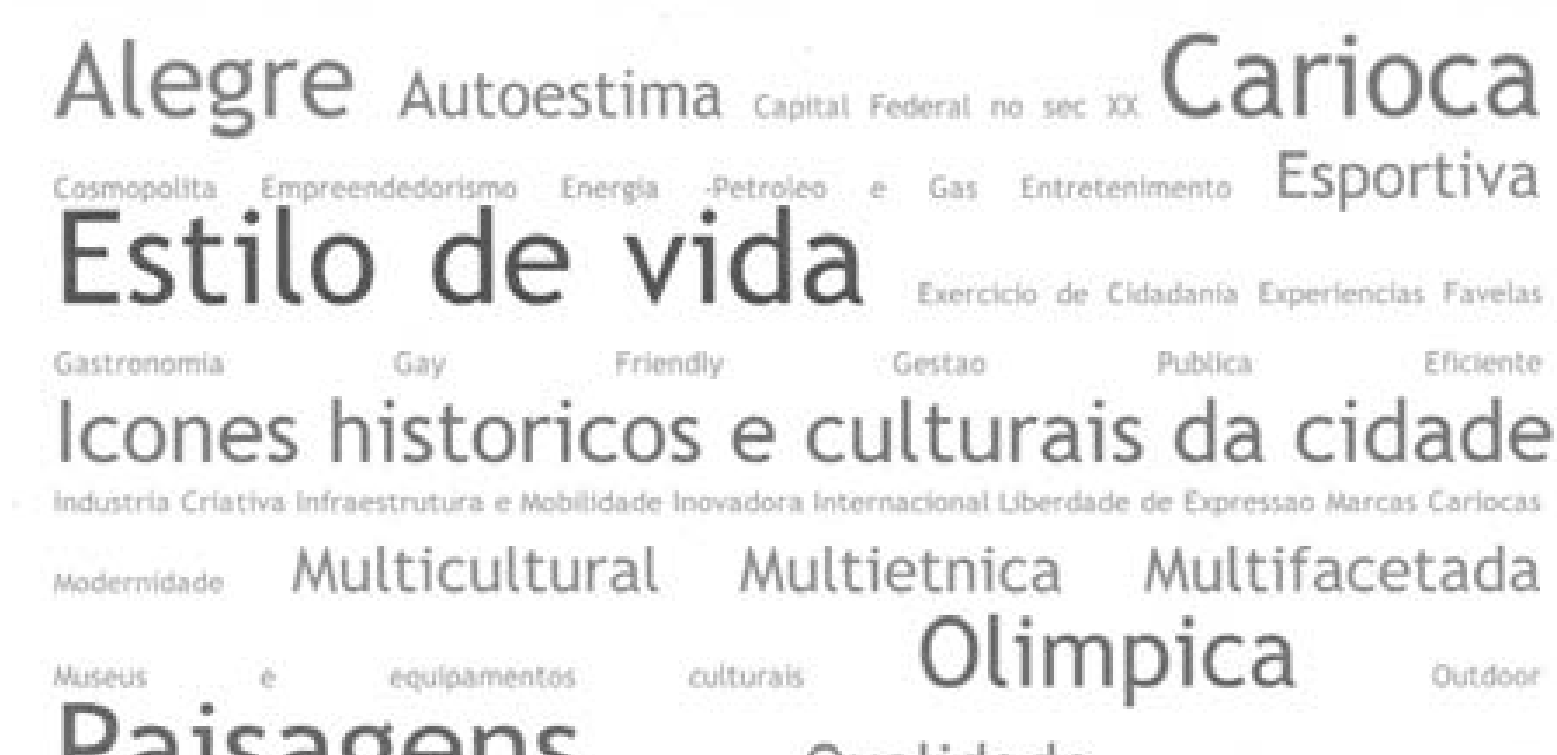

Paisagens

Particioatina Qualidade

\section{Turismo}

Fonte: Elaborado pela autora com o uso do sistema Tag Crowd.

Disponível em: http://www.tagcrowd.com. Acessado em 02/2016.

\section{CONSIDERAÇÕES FINAIS}

A vivência na cidade produz memórias o tempo todo naqueles que moram ou visitam o lugar e se tornam ótimos insumos na construção das narrativas corporativas. Quando empresas se propõem a lançar produtos e serviços relacionandoos à cidade ou quando são percebidas por representarem esse lugar elas estão acionando a memória afetiva que seus consumidores têm com o lugar. Trata-se de um movimento em mão dupla, de uma narrativa articulada entre marcas: a cidade nos produtos e os produtos na cidade. Ambos, marcas corporativas de produtos ou serviços e marca de cidade agregam uma percepção positiva nos seus públicos de relacionamento.

Segundo o Reputation Institute (2014), a reputação da marca de cidade, entre outros aspectos, também está relacionada ao pressuposto de o lugar ter produtos e serviços locais de qualidade e marcas conhecidas. Sendo assim, possuir marcas que em suas narrativas reforçam positivamente elementos da identidade da marca Rio contribuiu na construção de uma reputação positiva da cidade no contexto global, como destacado no início deste artigo.

A importância de se ter produtos de qualidade que representem o lugar e sua marca, assim como ter uma marca de lugar forte que chancele os produtos e serviços daquela região, também está presente nos trabalhos de Simon Anholt (2006) e da Saffron (2013). Nesse aspecto, a cidade do Rio de Janeiro reforça elementos de sua identidade nacionalmente e internacionalmente através das narrativas das marcas corporativas, como foi demosntrado ao longo desse artigo. Entretanto, a marca Rio ainda necessita reforçar seus demais elementos identitários e gerir sua reputação a fim de chancelar outros produtos e serviços locais. 
Quando as empresas lançam produtos e serviços com inspiração no Rio de Janeiro, a incorporação dos elementos da marca Rio ocorre no que Aaker (1996) chama de identidade nuclear da marca. Ou seja, tais produtos e serviços, carregam a marca Rio em sua essência central e atemporal e que permanece mais constante à medida que a marca se desloca para novos mercados. No caso das marcas eleitas como "marcas cariocas", a incorporação dos elementos da marca Rio ocorre na identidade expandida, ou seja, eles proporcionam textura e integridade à marca de produtos e serviços articulando-se em uma via de mão dupla com seus públicos (Aaker, 1996). Os casos estudados revelaram que a articulação entre essas diferentes dimensões do sistema de identidade de marca de Aaker (1996) favorece a agregação de valor tanto às marcas corporativas e de produtos e serviços quanto à marca Rio.

Vendo isso como uma estratégia de comunicação corporativa, é natural que as empresas busquem se associar a elementos da marca que não apresentem possibilidade de questionamentos, se afastando daqueles que são mais suscetíveis às crises de imagem da cidade. Nesse aspecto, o estudo demonstrou que os elementos das evidências físicas, principalmente nas dimensões produtiva e política não são explorados pelas corporações. Os aspectos da marca mais referenciados pelas narrativas das corporações são aqueles inseridos nas evidências simbólicas, principalmente nas dimensões dos atributos intangíveis e nas conexões.

Diversas narrativas em relação à marca da cidade são construídas continuamente por diferentes públicos. Por parte do gestor público que está capitaneando a marca da cidade, existe pouco ou quase nenhum controle sobre esse mosaico de narrativas. Entretanto, tais narrativas influenciam de forma decisiva a formação da imagem da marca da cidade. No caso das narrativas corporativas, sua capacidade de amplificar a visibilidade dos elementos associadosà marca da cidade cresce de forma exponencial, se comparada à capacidade do próprio gestor público de dar essa mesma visibilidade. Soma-se a isso o fato de que narrativas sobre a cidade construídas por públicos que não sejam gestores da marca tendem a ter melhor aceitação por parte do público.

Essa dinâmica, em mão dupla, de associações e produção de narrativas articuladas amplia significativamente as possibilidades de se construir uma marca de cidade com maior aderência junto aos públicos da organização. Nesse sentido, é importante que exista clara articulação entre a identidade da marca da cidade, a identidade corporativa e o posicionamento dos produtos e serviços produzidos localmente, de forma que fique fácil para o público compreender tal articulação.

Feito isso, a agregação de valor para ambos é muito eficaz para dar robustez à marca da cidade e reputação aos produtos e serviços. Esse movimento exige um esforço direcionado de criação de parcerias entre poder público e empresas privadas e uma gestão contínua da identidade e da imagem da marca.

\section{REFERÊNCIAS}

AAKER, David. Criando e administrando marcas de sucesso. São Paulo: Futura, 1996.

ANHOLT, Simon. The Anholt-GMI City Brands Index: how the world sees the world's cities. Place Branding and Public Diplomacy 2, n. 1, p. 18-31, Jan. 2006.

BARTHES, Roland The semiotic challenge. Oxford: Basil Blackwell, 1993.

BERRONE, Pascual; RICART, Joan Enric. lese cities in motion index 2016. Navarra: lese Business School, University of Navarra, 2016.

BROWNE, Rodrigo. Rio de Janeiro inspira nova marca de hotel. 22 de outubro de 2015. Disponível em: <https://www. bemparana.com.br/noticia/411623/rio-de-janeiro-inspira-uma-nova-marca-de-hotel>. Acesso em: out. 2015. 
CR PRESS Assessoria de Comunicação. Coleção Rio de Janeiro por Oscar Metsavaht exclusiva para Riachuelo em edição limitada. Riachuelo. 20 de outubro de 2010. Disponível em: <http://www.riachuelo.com.br/a-riachuelo/imprensa/releases/ colecao-rio-de-janeiro-por-oskar-metsavaht-exclusiva-para-riachuelo-em-edicao-limitada/292>. Acesso em: out. 2010.

DIAS, Flávia. Lançamento: coleção da Havaianas homenageia orla carioca. 17 de outubro de 2015. Disponível em: <http:// diasestilosos.com.br/2015/10/lancamento-colecao-da-havaianas-homenageia-orla-carioca.html>. Acesso em: out. 2015.

FFW. Coleção verão 2016 da Melissa é inspirada no Rio de Janeiro. 11 de maio de 2015. Disponível em: <http://ffw.com.br/ noticias/moda/colecao-verao-2016-da-melissa-e-inspirada-no-rio-de-janeiro-125/>. Acesso em: out. 2015.

FREITAS, Ricardo Ferreira. Comunicação e espaços urbanos de consumo: o imaginário dos shopping centers. In: FREITAS, Ricardo Ferreira; OLIVEIRA, Janete da Silva (orgs.). Olhares urbanos: estudos sobre a metrópole comunicacional. São Paulo: Summus, 2011. p. 11-27.

FREITAS, Ricardo Ferreira; FORTUNA, Vania Oliveira. 0 Rio de Janeiro continua lindo, o Rio de Janeiro continua sendo 0 grande palco brasileiro de megaeventos. In: CONGRESSO BRASILEIRO DE CIÊNCIAS DA COMUNICAÇÃO, XXXI, Natal (RN), 2-6 set. 2008. Anais... Natal, RN: Intercom, 2008.

KAVARATZIS, Michalis. From city marketing to city branding: towards a theoretical framework for developing city brands. Place Branding, n. 1, p. 58-73, 2004.

KUNSCH, Margarida. Planejamento de relações públicas na comunicação integrada. 4. ed. - rev. atual. e ampl. São Paulo: Summus, 2003.

NASSAR, Paulo. A história da Volks está sendo esquecida. Terra Magazine, 3 set. 2006. Disponível em: <http://terramagazine. terra.com.br/interna/0,,0l1119479-El6786,00-A+historia+da+Volks+esta+sendo+esquecida.html>. Acesso em: 7 out. 2015.

OLIVEIRA FILHO, Luiz Chrysostomo de; GIAMBIAGI, Fabio. Perspectivas de uma cidade em transformação. In: GIAMBIAAGI, Fabio (org.). Depois dos jogos: pensando o rio para depois de 2016. Rio de Janeiro: Elsevier, 2015. p. 3-30.

OLIVEIRA, Rita Lírio de. 0 tempo é chegado: a memória como meio de produzir e preservar identidades. Revista Reflexões, v. 1, n. 1 p. 5-20, 2009.

REIS, Patríca Cerqueira. Rio de Janeiro, uma cidade global? Uma reflexão sobre a construção da marca Rio. Tese (Doutorado em Ciências da Comunicação) - Escola de Comunicação e Artes, Universidade de São Paulo, São Paulo, 2016.

RI - Reputation Institute. 2014 City rep trak: the world's most reputable cities. 2014.

RIO. Plano estratégico da prefeitura do Rio de Janeiro 2013-2016. Rio de Janeiro: Prefeitura do Rio de Janeiro, 2013.

SAFFRON Brand Consultants. The Saffron European City Brand Barometer: revealing wich cities get the brands they deserve by Jeremy Hildreth. London: Saffron Brand Consultants, 2013.

SÁNCHEZ, Fernanda. A reinvenção das cidades para um mercado mundial. Chapecó, SC: Argos, 2010.

TORINO, Isabel Halfen da Costa. A memória social e a construção da identidade cultural: diálogos na contemporaneidade. eumed.net, dez. 2013. Disponível em: <http://www.eumed.net/rev/cccss/26/memoria-social.html>. Acesso em: 4 out. 2015. 
UNILEVER. Kibon e Farm se unem e lançam picolé Mate com Limão. 06 de janeiro de 2015. Disponível em: <http://www. unilever.com.br/media-centre/pressreleases/2015/kibon-e-farm-se-unem-e-lancam-picole-mate-com-limao.aspx>. Acesso em: out. 2015.

URANI, André; GIAMBIAGI, Fabio. Rio: a hora da virada. Rio de Janeiro:Leader, 2011.

VAINER, Carlos. A cidade como logomarca: a lógica da cidade-empresa. O Globo, 6 de agosto de 2011: Caderno Prosa \& Verso.

YANAZE, Mitsuru Higuchi. Gestão de marketing e comunicação: avanços e aplicações. 2. ed. São Paulo: Saraiva, 2011.

YIN, Robert K. Estudo de caso: planejamento e métodos. 2. ed. Porto Alegre, RS: Bookman, 2001.

Artigo recebido em 02.03.2016 e aprovado em 11.06.2016. 